\title{
Short- and long-term mortality associated with new-onset atrial fibrillation after coronary artery bypass grafting: A systematic review and meta-analysis
}

\author{
Roop Kaw, MD, ${ }^{\text {a,b }}$ Adrian V. Hernandez, MD, MSc, PhD, ${ }^{\mathrm{c}}$ Iqbal Masood, MD, ${ }^{\mathrm{a}}$ A. Marc Gillinov, MD, ${ }^{\mathrm{d}}$ \\ Walid Saliba, MD, ${ }^{\mathrm{e}}$ and Eugene H. Blackstone, $\mathrm{MD}^{\mathrm{c}, \mathrm{d}}$
}

\begin{abstract}
Objectives: Our objectives were to evaluate short- and long-term mortality associated with new-onset atrial fibrillation after coronary artery bypass grafting and to identify preoperative and intraoperative patient characteristics associated with new-onset atrial fibrillation.
\end{abstract}

\begin{abstract}
Methods: Three independent investigators comprehensively reviewed the literature using Medline from 1960, Web of Science from 1980, and Scopus from 1960. All searches were done through December 2009. Selected cohort studies were used to evaluate associations between new-onset atrial fibrillation after coronary artery bypass grafting or coronary bypass plus valve and short-term mortality (defined as 30-day or in-hospital mortality) and long-term mortality (defined as mortality $\geq 6$ months). We excluded studies involving atrial flutter, offpump coronary bypass, and isolated valve surgery. Heterogeneity among studies was accounted for by metaanalysis with random-effects models.
\end{abstract}

Results: Eleven studies $(\mathrm{n}=40,112)$ met our inclusion criteria. New-onset atrial fibrillation was associated with higher short-term mortality $(3.6 \%$ vs $1.9 \%$; odds ratio [OR], $2.29 ; 95 \%$ confidence interval [CI], $1.74-3.01 ; P<.00001$; heterogeneity of effects, $P=.002)$. Mortality risks at 1 year and 4 years were 2.56 (95\% CI, 2.14-3.08) and 2.19 (95\% CI, 1.97-2.45; $P<.0001)$, respectively. Older age, lower ejection fraction, history of hypertension, heart failure, prior stroke, peripheral arterial disease, and longer cardiopulmonary bypass and aortic clamp times were associated with new-onset atrial fibrillation. Preoperative use of $\beta$-blockers reduced occurrence of new-onset atrial fibrillation (OR, 0.94 [95\% CI, 0.88$1.01 ; P=.08]$ ), whereas angiotensin-converting enzyme inhibitors increased it (OR, $1.20[95 \% \mathrm{CI}$, $1.11-1.29], P<.00001)$.

Conclusions: New-onset atrial fibrillation after coronary artery bypass grafting appears to increase short- and long-term mortality. Preoperative use of $\beta$-blockers, avoidance of angiotensin-converting enzyme inhibitors, and shorter cardiopulmonary bypass and aortic clamp times potentially reduce occurrence of new-onset atrial fibrillation. (J Thorac Cardiovasc Surg 2011;141:1305-12)

New-onset atrial fibrillation (AF) remains the most common complication after cardiac surgery, with little change over the past 2 decades. It occurs in $25 \%$ to $40 \%$ of patients after coronary artery bypass grafting $(\mathrm{CABG})$ and in up to $62 \%$ after a combined CABG and valve procedure. $^{1}$

\footnotetext{
From the Medicine Institute, Department of Hospital Medicine, ${ }^{a}$ Anesthesia Institute, Department of Outcomes Research, Lerner Research Institute, ${ }^{b}$ Department of Quantitative Health Sciences, Heart and Vascular Institute, ${ }^{\mathrm{c}}$ Department of Thoracic and Cardiovascular Surgery, ${ }^{\mathrm{d}}$ and Electrophysiology Laboratory, ${ }^{\mathrm{e}}$ Cleveland Clinic, Cleveland, Ohio.

Disclosures: Authors have nothing to disclose with regard to commercial support.

R.K. and A.V.H. have contributed equally to this study.

Received for publication May 19, 2010; revisions received Sept 20, 2010; accepted

for publication Oct 24, 2010; available ahead of print Jan 19, 2011.

Address for reprints: Roop Kaw, MD, Department of Hospital Medicine and Outcomes Research, Anesthesia. Medicine Institute, Cleveland Clinic, Desk A-13. 9500 Euclid Ave,Cleveland, OH 44195 (E-mail: Kawr@ccf.org). $0022-5223 / \$ 36.00$

Copyright (c) 2011 by The American Association for Thoracic Surgery doi:10.1016/j.jtcvs.2010.10.040
}

New-onset AF is widely known to increase morbidity after cardiac surgery, ${ }^{2-5}$ and several studies have shown increased in-hospital and long-term mortality, but this association is not well established or clearly understood. ${ }^{2-8}$ However, other studies have not reported new-onset AF to have an independent effect on in-hospital mortality. ${ }^{9}$ Additionally, information related to new-onset AF comes mostly from single-institution studies. Therefore, the primary purpose of our meta-analysis was to evaluate the short- and long-term mortality of new-onset AF after CABG. Secondarily, we also evaluated preoperative, intraoperative, and postoperative variables associated with the occurrence of new-onset AF.

\section{METHODS}

\section{Study Selection}

We conducted a comprehensive literature search using Medline from 1960 through December 2009, The Web of Science from 1980 through December 2009, and Scopus from 1960 through December 2009. We 


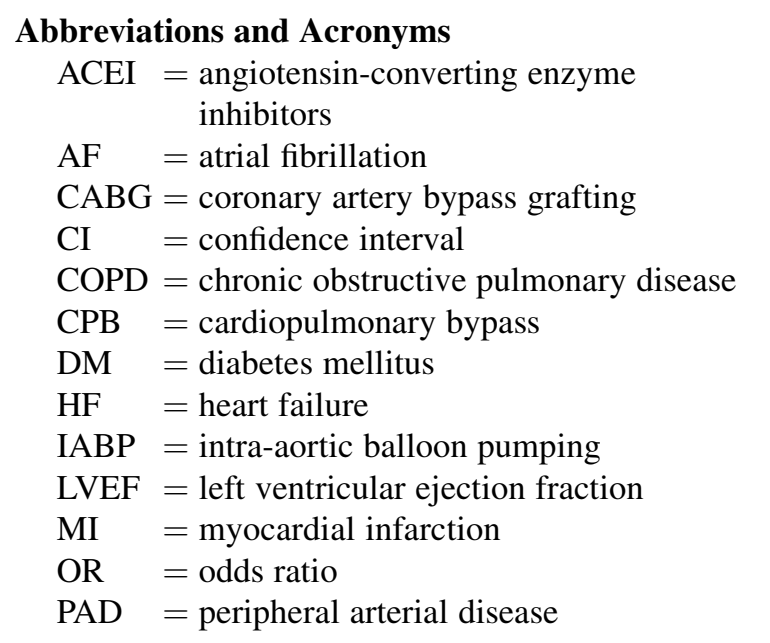

restricted our search to observational cohort studies and used the following key words: $\mathrm{AF}$, cardiac surgery or cardiac surgical procedures or $\mathrm{CABG}$ surgery, mortality or death or outcomes, and determinants or risk factors. We also used MeSH and TIAB terms for the Medline search. All published studies that evaluated the occurrence of short-term (in-hospital or within 30 days) and long-term ( $\geq 6$ months) mortality in patients with new-onset AF after CABG with or without valve surgery were identified. In these studies, new-onset $\mathrm{AF}$ was defined as persistent $\mathrm{AF}$ of any duration at any time postoperatively by physician assessment on the basis of a rhythm strip or 12-lead electrocardiographic recording. Results of the combined search were limited to studies of adult humans published in English, Spanish, French, and German.

A list of retrieved articles was reviewed independently by 3 investigators (R.K., I.M., and A.V.H.) to choose potentially relevant articles. When multiple articles for a single study had been published, we used the latest publication and supplemented it, if necessary, with data from earlier publications. Only studies that clearly identified mortality and perioperative variables in tables or text for both new-onset AF and nonnew-onset $\mathrm{AF}$ groups were included in the final data set. We excluded studies of atrial flutter and tachycardia, off-pump CABG procedures, and isolated valve surgery. All studies in which the main purpose of the publication was to evaluate a treatment or intervention were also excluded, unless preoperative or intraoperative information was useful for the purpose of our study.

\section{Data Extraction}

Data were extracted by 3 investigators (I.M., A.V.H., and R.K.) and the results compiled. Disagreement was resolved by consensus. Using a standardized data extraction form, we collected information on lead author, publication year, study design, sample size, and proportion of patients with early and late mortality. The following preoperative summary information was collected from each study for the new-onset and non-new-onset AF groups: age, gender, history of hypertension, myocardial infarction (MI), heart failure (HF), diabetes mellitus (DM), chronic renal insufficiency, stroke, peripheral arterial disease (PAD), chronic obstructive pulmonary disease (COPD), and smoking; left ventricular ejection fraction (LVEF), use of beta-blockers ( $($-blockers), angiotensin-converting enzyme inhibitors (ACEI) and intra-aortic balloon pump (IABP). Information about intraoperative (cardiopulmonary bypass [CPB] time, use of IABP, aortic clamp time, and use of inotropes) and postoperative outcomes (length of hospital stay, respiratory failure, postoperative HF, stroke, and MI) was also collected.

\section{Validity and Study Quality Assessment}

Prospective cohort studies were considered to be of higher quality than retrospective cohort studies. Case-control studies that were specifically designed to assess the influence of risk factors on occurrence of newonset AF were considered to be of higher quality than studies that used a nested case-control design, either by identifying cases of new-onset AF by hospital discharge registers or by using existing patient registries.

\section{Statistical Analysis}

First, we evaluated the association between new-onset AF after CABG and short- and long-term all-cause mortality. We used the Mantel-Haenszel method to calculate pooled odds ratios (OR) and $95 \%$ confidence interval (CI) methods for mortality. ${ }^{10}$ Because mortality statistics are scarce and the proportion of new-onset AF patients low, the Mantel-Haenszel method was preferred. We also used DerSimonian and Laird random effects models, and statistical heterogeneity was evaluated as described elsewhere. ${ }^{11}$ Publication bias was assessed graphically with funnel plots. We did not have access to individual patient-level data, and therefore no adjustment was possible for potential confounders of the association between new-onset AF and mortality. We used Review Manager (RevMan, version 5.0 for Windows, Oxford, United Kingdom; The Cochrane Collaboration, 2008).

Long-term mortality was reported at different time points (6 months, 1 and 4 years). We calculated unreported mortality from the reported Kaplan-Meier curves when available. With the exception of one, most studies did not report the number of patients at risk per time point, which discount patients who died or were lost to follow-up, and we could not use this information in the analysis. Given the circumstances under which IABP is used, we chose to combine the reported intraoperative and postoperative use for purposes of analysis. Preoperative IABP use was analyzed separately.

\section{Sensitivity Analysis}

To explore the strength of the association between new-onset AF and mortality, we removed studies with fewer than 500 patients with newonset $\mathrm{AF}$, removed studies whose populations underwent $\mathrm{CABG}$ plus valve surgery, and used fixed-effects models. After exclusion of studies with fewer than 500 patients, a total of 38,292 patients remained of whom 28,800 underwent CABG only. No differences were found between random and fixed models, and only random-effects models are reported.

We evaluated the association between patient characteristics (preoperative and intraoperative) and new-onset AF. We used the Mantel-Haenszel method to calculate pooled OR for categorical characteristics or mean difference for continuous characteristics and their $95 \%$ CIs. Also, because statistically significant clinical heterogeneity among studies was expected, we used the DerSimonian and Laird random-effects models. Statistical heterogeneity of effects was evaluated with the Cochran $\chi^{2}$ test and the $\mathrm{I}^{2}$ statistic. The overall effect was calculated with the $Z$ test. Finally, we described the associations between postoperative outcomes and new-onset $\mathrm{AF}$, which do not necessarily have a temporal relationship.

\section{RESULTS Study Characteristics}

A total of 927 citations were identified and screened, of which 46 were retrieved for more detailed information (Figure 1). Of these, 34 did not fit our criteria, major reasons for exclusion being inclusion of patients with AF preoperatively, heart transplantation, valve-only procedures, and aortic surgery. We chose 12 studies. We did not get a response from the authors of 1 study, and it was eliminated from the analysis. Thus, we finally included 11 cohort studies $^{2-9,12-14}\left(\mathrm{n}=40,112 ; 5\right.$ prospective $\left.\mathrm{e}^{2,5-8}\right)$, which were 


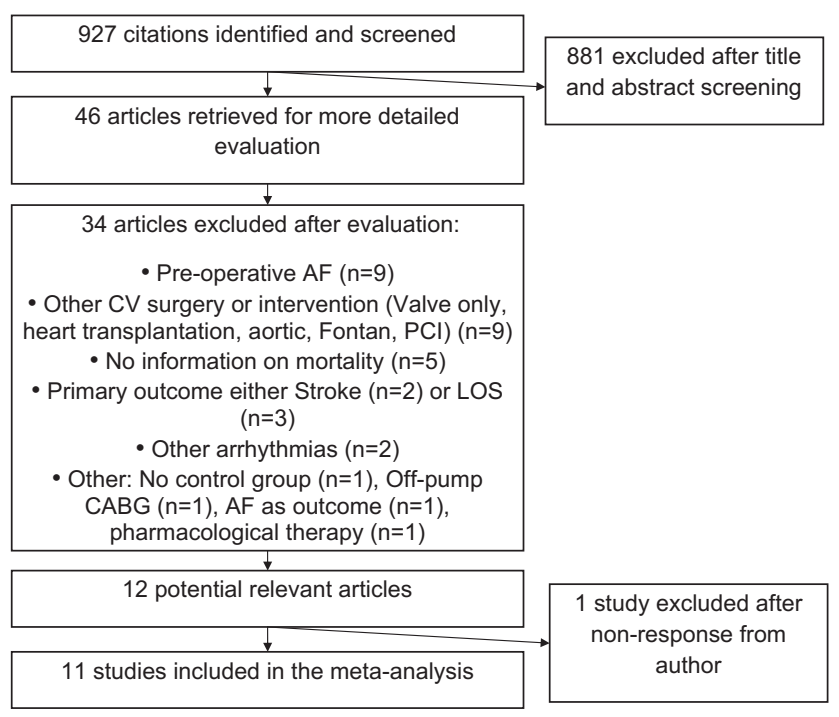

FIGURE 1. Search strategy profile of the meta-analysis. $A F$, Atrial fibrillation; $C V$, cardiovascular; $P C I$, percutaneous coronary intervention; $L O S$, low-output syndrome; $C A B G$, coronary artery bypass grafting.

published between 1996 and 2009 (Table 1). Overall, all patients underwent CABG, 97\% underwent CABG only (9 studies), and the remaining 2 studies $^{5,9}$ included patients who underwent $\mathrm{CABG}$ plus valve surgery.

\section{Description of Patient Characteristics}

On average, three quarters of patients were male and received B-blockers, two thirds had hypertension, $40 \%$ had prior MI or smoked, a quarter had DM, and $10 \%$ had prior stroke. The means \pm standard deviations for age and LVEF were $64 \pm 8$ years and $54 \% \pm 13 \%$, respectively. As shown in Table 1, patients were clinically heterogeneous among studies.

Intraoperative and postoperative information were not consistently reported across studies. Mean CPB and aortic clamp times were $92 \pm 35$ and $51 \pm 22$ minutes, respectively; only $2 \%$ of patients needed IABP. Inotrope use was reported in only 3 studies. ${ }^{3,4,14}$ Among the postoperative complications, respiratory failure $(10 \%)$ was the most common. Other complications were uncommon: HF 3\%, stroke $2 \%$, and MI $4 \%$. Mean postoperative length of stay was $7.3 \pm 4.2$ days.

\section{Association Between Postoperative Non-New-Onset AF and Both Short- and Long-Term Mortality}

All studies evaluated short-term mortality. New-onset AF was associated with higher short-term mortality (new-onset AF: 368/10,330 [3.6\%] vs non-new-onset AF: 552/29,772 [1.9\%]; OR, 2.29; 95\% CI, 1.74-3.01; $P<.00001$; Figure 2). There was important statistical heterogeneity among the mortality effects $\left(\mathrm{I}^{2}=64 \%, P=.002\right)$, and no evidence of publication bias. The association between new-onset AF and short-term mortality remained similar after removal of studies with fewer than 500 new-onset AF patients ${ }^{6,12,14}$ (OR, 2.34 [95\% CI, 1.75-3.13]), and after removal of the 2 studies including CABG plus valve surgery $^{5,9}$ (OR, 2.61 [95\% CI, 2.06-3.29]).

Five studies evaluated long-term mortality. ${ }^{3-5,7,8} \mathrm{New}$ onset AF was also associated with mortality at 1 year $^{3,4,7,8}$ (new-onset AF: 256/3728 [6.9\%] vs non-new-onset AF: 462/13,619 [3.4\%]; OR, 2.56 [95\% CI, 2.14-3.08]; $P<.00001$ ) and at 4 years $^{3,4,7,8}$ (new-onset AF: 574/3728 [15\%] vs non-new-onset AF: 1199/13,619 [8.8\%]; OR, 2.19 [95\% CI, 1.97-2.45]; $P<.00001$; Figure 3). These risks were similar to the short-term mortality risks. There was little statistical heterogeneity of the long-term risks among studies. Only 2 studies $^{4,8}$ evaluated mortality at 8 years, and risk of mortality was in the same direction (new-onset AF: 623/2164 [29\%] vs non-new-onset AF: $1140 / 6876 \quad[17 \%] ;$ OR, $2.01 \quad[95 \%$ CI, 1.80-2.25]; $P<.00001)$.

\section{Association of Preoperative, Intraoperative, and Postoperative Variables With Postoperative New- Onset AF}

Table 2 shows the associations between preoperative and intraoperative variables and postoperative new-onset AF. Older age, lower LVEF, prior stroke, and history of hypertension, $\mathrm{HF}$, and PAD were strongly associated with postoperative new-onset AF. History of MI and chronic renal insufficiency also were associated with increased the risk of new-onset AF, but in lower magnitude. Male gender, history of DM, and smoking were not associated with new-onset AF.

Preoperative use of $\beta$-blockers limitedly reduced the relative risk of new-onset $\mathrm{AF}$ by $6 \%$ (OR, $0.94[95 \% \mathrm{CI}$, $0.88-1.01], P=.08)$, and the effects among studies were consistent $(P$ for heterogeneity $=.4)$. Use of ACEI was associated with an increased risk of new-onset AF (OR, 1.20 [95\% CI, 1.11-1.29]; $P<.00001)$. However, this association was based on only 3 studies. Four studies $3,6,7,9$ reported preoperative IABP and this was associated with new-onset AF (OR, 1.46 [95\% CI, 1.25-1.70]; $P<.00001$ ).

Six studies ${ }^{2,4,5,8,13,14}$ reported that longer CPB time was associated with new-onset $\mathrm{AF}$ (mean difference, 4.73 [95\% CI, 2.40-7.05]; $P<.0001$ ), and 5 studies $^{2,4,8,13,14}$ reported that longer aortic clamp time was associated with new-onset $\mathrm{AF}$ (mean difference, 4.13 [95\% CI, 1.816.45]; $\quad P=.0005$ ). Five studies ${ }^{2,6,7,9,14}$ reported postoperative and 1 study $^{4}$ reported intraoperative IABP use. We found a weak relation between intraoperative/postoperative use of IABP and new-onset AF (OR, 1.57 [95\% CI, 0.92-2.66]; $P=.10$ ). Use of intraoperative inotropes was also associated with new-onset AF (OR, $2.05[95 \%$ CI, 1.15-3.65]; $P=.02$ ). All these associations were heterogeneous among studies. 
TABLE 1. Preoperative patient characteristics in studies included in the meta-analysis

\begin{tabular}{|c|c|c|c|c|c|}
\hline Study reference, year & $\mathbf{N}$ & $\%$ CABG only & Type of overall mortality & $\begin{array}{c}\text { Age }(\mathrm{y}), \\
\text { mean }(\mathrm{SD})\end{array}$ & $\begin{array}{l}\text { Men, } \\
\text { n (\%) }\end{array}$ \\
\hline Ahlsson et al, ${ }^{8} 2009$ & 1,419 & 100 & IHM up to $9 \mathrm{y}$ & $65.7(9.1)$ & $1,068(75)$ \\
\hline Almassi et al, ${ }^{5} 1997^{*}$ & 3,855 & 81 & IHM 6 mo & $63.7(9.4)$ & $3,795(98)$ \\
\hline Aranki et al, ${ }^{6} 1996$ & 5,70 & 100 & IHM & $71.5 \dagger$ & 395 (69) \\
\hline Echahidi et al, ${ }^{13} 2007$ & 5,086 & 100 & IHM & $64.0(7.1)$ & $3,892(77)$ \\
\hline Hravnak et al, ${ }^{12} 2002$ & 814 & 100 & IHM & $65.5(9.5)$ & $546(67)$ \\
\hline Kalavrouziotis et al, ${ }^{9} 2007 \dagger$ & 7,347 & 92 & IHM & NA & $5,433(74)$ \\
\hline Mariscalco et al, ${ }^{7} 2008$ & 1,832 & 100 & IHM up to $6 \mathrm{y}$ & $65.2(8.6)$ & $1,448(79)$ \\
\hline Mariscalco et al, ${ }^{4} 2009$ & 7,621 & 100 & IHM up to $12 \mathrm{y}$ & $64.6(8.6)$ & $5,830(77)$ \\
\hline Mathew et al, ${ }^{2} 2004$ & 4,657 & 100 & IHM & $63.7(9.2)$ & $3,716(80)$ \\
\hline Nisanoglu et al, ${ }^{14} 2007$ & 426 & 100 & IHM & $70.1(4.4)$ & $296(69)$ \\
\hline Villareal et al,${ }^{3} 2004$ & 6,475 & 100 & IHM up to $4 \mathrm{y}$ & $63.1(10.5)$ & $4,780(74)$ \\
\hline Total & 40,112 & 97 & & $64.4(7.6)$ & $31,199(78)$ \\
\hline
\end{tabular}

$C A B G$, Coronary artery bypass grafting; $S D$, standard deviation; $H T N$, hypertension; $D M$, diabetes mellitus; $C O P D$, chronic obstructive pulmonary disease; $L V E F$, left ventricular ejection fraction; $M I$, myocardial infarction; $B B$, Use of $B$-blockers; $I H M$, in-hospital mortality; $N A$, not available; stroke, prior stroke. *Includes patients with CABG only and CABG plus valve. †Median. $\ddagger$ Number of patients with $\mathrm{LVEF}>40 \%$.

We also evaluated the relationship between postoperative outcome variables and new-onset AF, although most studies did not specify whether these complications preceded or followed the occurrence of new-onset AF. Postoperative stroke (OR, $2.23[95 \% \mathrm{CI}, 1.78-2.80])$ and respiratory failure (OR, 2.30 [95\% CI, 1.71-3.11]) were associated with higher risk of new-onset AF. Postoperative MI (OR, 0.98 [95\% CI, 0.56-1.71]) and HF (OR, 1.82 [95\% CI, 0.78-4.23]) were not related to new-onset AF. Patients experiencing new-onset AF had a longer postoperative length of stay by median 1.48 days $(95 \% \mathrm{CI}$, $1.09-1.87$ days)

\section{DISCUSSION}

\section{Principal Findings}

Mortality. Our analysis provides convincing evidence that both short- and long-term mortality are increased when new-onset $\mathrm{AF}$ is diagnosed after CABG. The increase in in-hospital mortality was seen in all studies included in the meta-analysis. Although heterogeneous, the effect persisted after excluding studies with small numbers of patients and studies of combined CABG and valve surgery. The effect of new-onset AF on mortality persisted at 6 months, 1 year, and 4 years and was similar to short-term mortality risk, although only a few long-term studies were available.

Earlier studies did not report increased mortality from new-onset AF after cardiac surgery. Recently, Kalavrouziotis and associates ${ }^{9}$ did not report new-onset $\mathrm{AF}$ to have an independent effect on in-hospital mortality (OR, 0.8 [95\% CI, 0.6-1.2]) in 2 comparable risk-adjusted and propensity-matched groups of patients after cardiac surgery. The study, however, lacked data on use of rate or rhythm control medication postoperatively. The earliest data on

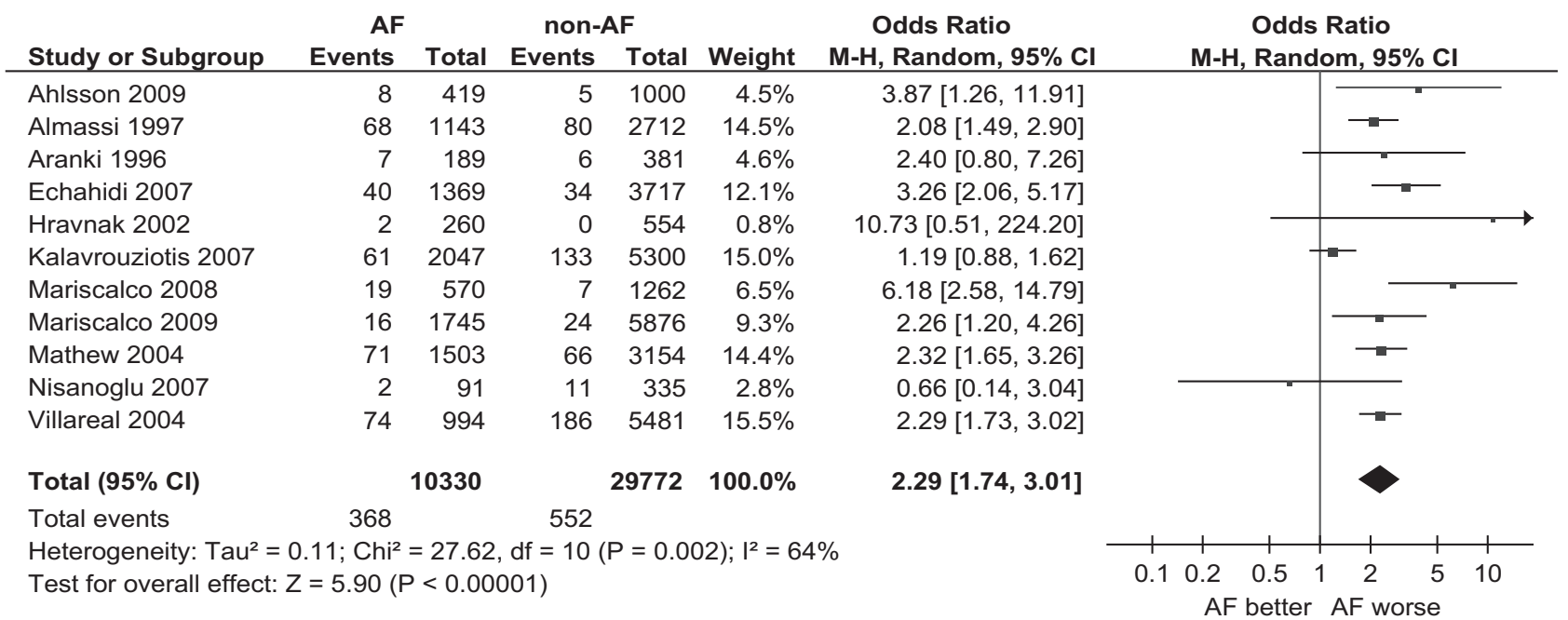

FIGURE 2. Short-term mortality risks associated with new-onset atrial fibrillation. $A F$, Atrial fibrillation; $M-H$, Mantel-Haenszel; $C I$, confidence interval. 
TABLE 1. Continued

\begin{tabular}{|c|c|c|c|c|c|c|c|}
\hline $\begin{array}{l}\text { HTN, } \\
\text { n (\%) }\end{array}$ & $\begin{array}{l}\text { DM, } \\
\text { n (\%) }\end{array}$ & $\begin{array}{l}\text { Stroke, } \\
\text { n (\%) }\end{array}$ & $\begin{array}{l}\text { COPD, } \\
\text { n (\%) }\end{array}$ & $\begin{array}{c}\text { Smoking, } \\
\text { n (\%) }\end{array}$ & $\begin{array}{c}\text { LVEF, } \\
\text { mean (SD) }\end{array}$ & $\begin{array}{c}\text { MI, } \\
\text { n (\%) }\end{array}$ & $\begin{array}{c}\text { BB use, } \\
\text { n (\%) }\end{array}$ \\
\hline $531(37)$ & 243 (17) & $95(7)$ & NA & 835 (58) & 57.7 (12) & $825(58)$ & NA \\
\hline 2,273 (59) & NA & 692 (18) & 589 (15) & $1,012(26)$ & NA & $1,972(51)$ & 2,265 (59) \\
\hline $336(59)$ & $173(30)$ & 90 (16) & $51(9)$ & $144(25)$ & NA & $343(60)$ & $430(75)$ \\
\hline $3,272(64)$ & $1,594(31)$ & $253(5)$ & 509 (10) & NA & $59.6(14)$ & $2,490(49)$ & $4,031(79)$ \\
\hline NA & $230(28)$ & NA & $91(11)$ & NA & NA & $236(29)$ & NA \\
\hline $4,479(61)$ & $2,430(33)$ & 932 (13) & 994 (14) & NA & $6,463 \ddagger$ & NA & $6,189(84)$ \\
\hline $1,017(56)$ & $491(27)$ & $106(6)$ & $138(8)$ & 444 (24) & $54.7(11.1)$ & 397 (51) & 1,279 (70) \\
\hline $4,631(61)$ & $1,676(22)$ & $659(9)$ & NA & NA & NA & NA & NA \\
\hline 3,113 (67) & $1,442(31)$ & $481(10)$ & $532(11)$ & NA & NA & $2,952(63)$ & 3,235 (69) \\
\hline $178(42)$ & 79 (19) & $100(23)$ & $89(21)$ & $211(50)$ & $48.2(10.6)$ & $309(73)$ & $180(42)$ \\
\hline $4,421(68)$ & $710(11)$ & $385(6)$ & 1,497 (23) & $3,503(54)$ & $49.3(13.2)$ & 1,017 (16) & NA \\
\hline $24,252(62)$ & $9,068(25)$ & 3,793 (10) & 4,490 (14) & $6,149(42)$ & $54.1(12.7)$ & $11,081(44)$ & $17,609(74)$ \\
\hline
\end{tabular}

the association of new-onset AF after cardiac surgery with intermediate-term (6-month) mortality were reported by Almassi and colleagues 5 (new-onset AF 9.4\% vs nonnew-onset AF $4.2 \% ; P<.001)$. Villareal and associates ${ }^{3}$ also found that new-onset $\mathrm{AF}$ was associated with a higher risk of in-hospital mortality (OR, 1.5 [95\% CI, 1.3-1.8]; $P<.0001$ ). So that its impact on estimates of later outcomes would be reduced, in-hospital mortality was censored, but the adverse mortality persisted after case-control matching (OR, 3.4 [95\% CI, 1.6-7.5]). More important, however, the etiology and pathophysiology of new-onset AF still remain largely unclear. ${ }^{15}$

Five studies looked at long-term mortality from newonset $\mathrm{AF}$ after $\mathrm{CABG} .^{3-5,7,8}$ Of these, only 2 studies $^{7,8}$ specifically investigated autopsy results, with 82 and 331 deaths, respectively. Mariscalco and colleagues ${ }^{7}$ followed 1832 patients ( 570 with new-onset $\mathrm{AF}$ ) for up to 6 years and Ahlsson and colleagues ${ }^{8}$ followed 1419 patients (419 with new-onset $\mathrm{AF}$ ) up to 9 years after CABG. A higher number of deaths owing to cerebral events (51/82 vs 20/ 419) was reported by Mariscalco and colleagues, ${ }^{7}$ although some of the difference in mortality resulting from cerebral events could be related to how new-onset AF was treated. Direct-current cardioversion was tried at the first postoperative visit, after previously attempted pharmacologic cardioversion had failed. In Ahlsson and colleagues' study, ${ }^{8}$ the main treatment for new-onset AF was electrical as opposed to pharmacologic cardioversion (with amiodarone) and ischemic/embolic strokes were confirmed in all patients by computed tomography.

More patients (70/140) with new-onset AF died of cardiac causes (including MI and congestive HF) in Ahlsson and colleagues' study ${ }^{8}$ than of similar causes in the Mariscalco study ${ }^{7}$ (31/82). The number of deaths from acute MI and HF were too low for any predictive estimate but seemed to occur constantly during the follow-up time frame. A constant hazard rate was demonstrated in a subsequent study, ${ }^{4}$ which did not report autopsy data. There seemed to be an earlier trend to mortality from cerebral events in the study by Mariscalco and colleagues. ${ }^{7}$ To see whether there were any differences over time, Ahlsson and associates ${ }^{8}$ separated the patients postoperatively into groups with and without $\mathrm{AF}$, but no differences were noted with respect to any single cause of death.

The mechanisms by which new-onset $\mathrm{AF}$ is associated with higher mortality are purely speculative and beyond the scope of our analysis. It is currently unknown whether patients who have new-onset AF can also have left ventricular dysfunction, chronic or persistent AF, or thromboembolic phenomena. Some case series and animal experiments have shown that $\mathrm{AF}$ with rapid ventricular response can predispose to dilated cardiomyopathy within

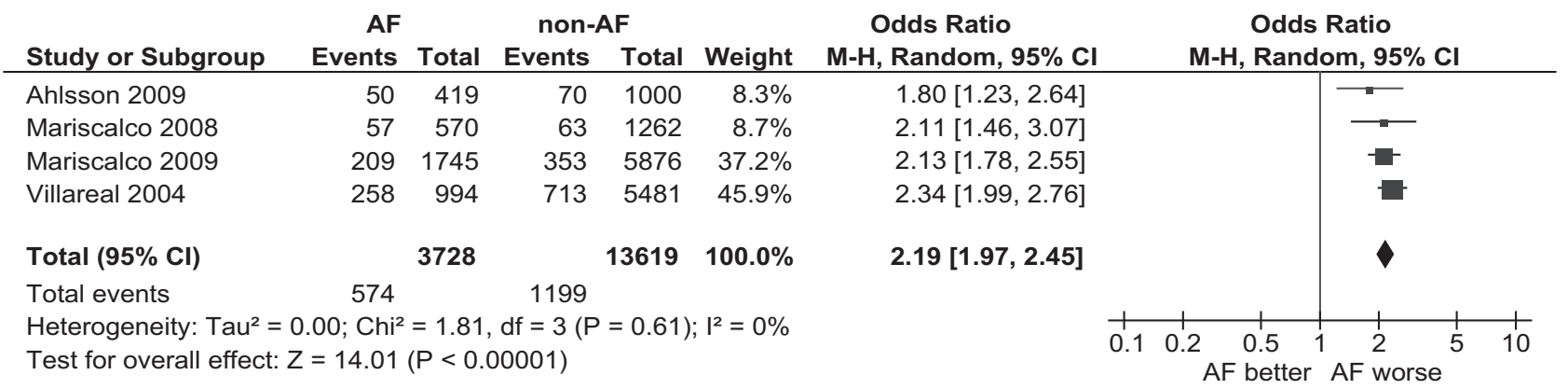

FIGURE 3. Four-year mortality risks associated with new-onset atrial fibrillation. $A F$, Atrial fibrillation; $M-H$, Mantel-Haenszel; $C I$, confidence interval. 
TABLE 2. Association between preoperative, intraoperative, and postoperative variables and postoperative new-onset AF

\begin{tabular}{|c|c|c|c|c|c|c|}
\hline \multirow[b]{2}{*}{ Variable } & \multirow{2}{*}{$\begin{array}{l}\text { No. of } \\
\text { studies }\end{array}$} & \multicolumn{2}{|c|}{ New-onset AF* } & \multirow{2}{*}{$\begin{array}{c}\text { Association effect } \\
{[95 \% \text { CI }]}\end{array}$} & \multirow{2}{*}{$\begin{array}{l}P \text { for } \\
\text { effect }\end{array}$} & \multirow{2}{*}{$\begin{array}{c}P \text { for } \\
\text { heterogeneity }\end{array}$} \\
\hline & & Yes & No & & & \\
\hline \multicolumn{7}{|l|}{ Preoperative } \\
\hline Age (y) & 9 & $\begin{array}{l}68.2(6.3) \\
(\mathrm{n}=8,094)\end{array}$ & $\begin{array}{l}63.1(8.1) \\
(\mathrm{n}=24,091)\end{array}$ & MD 4.73 [4.01-5.45] & $<.00001$ & $<.00001$ \\
\hline Male gender & 11 & $\begin{array}{l}8,133 / 10,330 \\
(78.7 \%)\end{array}$ & $\begin{array}{l}23,068 / 29,772 \\
(77.5 \%)\end{array}$ & OR 1.04 [0.97-1.12] & .3 & .2 \\
\hline Hypertension & 10 & $\begin{array}{l}6,465 / 10,070 \\
(64.2 \%)\end{array}$ & $\begin{array}{l}17,786 / 29,218 \\
(60.9 \%)\end{array}$ & OR 1.19 [1.13-1.26] & $<.00001$ & .3 \\
\hline Prior stroke & 10 & $\begin{array}{l}1,229 / 10,070 \\
(12.2 \%)\end{array}$ & $\begin{array}{l}2,564 / 31,545 \\
(8.1 \%)\end{array}$ & OR 1.42 [1.16-1.72] & .0005 & $<.00001$ \\
\hline MI & 9 & $\begin{array}{l}3,236 / 6,457 \\
(50.1 \%)\end{array}$ & $\begin{array}{l}7,845 / 18,449 \\
(42.5 \%)\end{array}$ & OR 1.10 [1.02-1.17] & .01 & .3 \\
\hline $\mathrm{HF}$ & 5 & $\begin{array}{l}1,185 / 4,993 \\
(23.7 \%)\end{array}$ & $\begin{array}{l}2,487 / 14,870 \\
(16.7 \%)\end{array}$ & OR 1.39 [1.28-1.51] & $<.00001$ & .7 \\
\hline PAD & 8 & $\begin{array}{l}1,464 / 8,282 \\
(17.7 \%)\end{array}$ & $\begin{array}{l}3,321 / 24,501 \\
(13.6 \%)\end{array}$ & OR 1.37 [1.20-1.58] & $<.00001$ & .003 \\
\hline $\mathrm{DM}$ & 10 & $\begin{array}{l}2,464 / 9,187 \\
(26.8 \%)\end{array}$ & $\begin{array}{l}6,605 / 26,960 \\
(24.5 \%)\end{array}$ & OR 0.99 [0.90-1.10] & 0.9 & .007 \\
\hline Chronic renal insufficiency & 4 & $\begin{array}{l}299 / 3,702 \\
(8.1 \%)\end{array}$ & $\begin{array}{l}827 / 12,378 \\
(6.1 \%)\end{array}$ & OR 1.58 [1.11-2.24] & .01 & .008 \\
\hline COPD & 9 & $\begin{array}{l}1,367 / 8,166 \\
(16.7 \%)\end{array}$ & $\begin{array}{l}3,123 / 22,896 \\
(13.6 \%)\end{array}$ & OR 1.45 [1.35-1.56] & $<.00001$ & .9 \\
\hline Smoking & 6 & $\begin{array}{l}1,256 / 3,401 \\
(36.9 \%)\end{array}$ & $\begin{array}{l}4,895 / 11,156 \\
(43.9 \%)\end{array}$ & OR 0.90 [0.74-1.10] & .3 & .0007 \\
\hline $\operatorname{LVEF}(\%)$ & 5 & $\begin{array}{l}54.7(12.1) \\
(\mathrm{n}=3,443)\end{array}$ & $\begin{array}{l}54.0(13.3) \\
(\mathrm{n}=11,795)\end{array}$ & $\mathrm{MD}-0.92[-1.43,-0.40]$ & .0005 & .7 \\
\hline ß-Blocker use & 7 & $\begin{array}{l}5,049 / 6,899 \\
(73.2 \%)\end{array}$ & $\begin{array}{l}12,560 / 16,845 \\
(74.6 \%)\end{array}$ & OR 0.94 [0.88-1.01] & .08 & .4 \\
\hline ACEI use & 3 & $\begin{array}{l}1,875 / 4,120 \\
(45.5 \%)\end{array}$ & $\begin{array}{l}3,983 / 9,716 \\
(41.0 \%)\end{array}$ & OR 1.20 [1.11-1.29] & $<.00001$ & .7 \\
\hline \multicolumn{7}{|l|}{ Intraoperative } \\
\hline CPB time (min) & 6 & $\begin{array}{l}97.1(35.7) \\
(\mathrm{n}=6,270)\end{array}$ & $\begin{array}{l}90.0(35.4) \\
(\mathrm{n}=16,794)\end{array}$ & MD 4.73 [2.40-7.05] & $<.0001$ & .0003 \\
\hline AC time (min) & 5 & $\begin{array}{l}55.4(23.4) \\
(\mathrm{n}=5,127)\end{array}$ & $\begin{array}{l}49.9(21.6) \\
(n=14,082)\end{array}$ & MD 4.13 [1.81-6.45] & .0005 & $<.0001$ \\
\hline Use of IABP & 6 & $\begin{array}{l}161 / 6,145 \\
(2.6 \%)\end{array}$ & $\begin{array}{l}296 / 16,308 \\
(1.8 \%)\end{array}$ & OR 1.57 [0.92-2.66] & .1 & $<.0001$ \\
\hline Use of inotropes & 3 & $\begin{array}{l}685 / 2,830 \\
(24.2 \%)\end{array}$ & $\begin{array}{l}1,580 / 11,692 \\
(13.5 \%)\end{array}$ & OR 2.05 [1.15-3.65] & .02 & $<.00001$ \\
\hline \multicolumn{7}{|l|}{ Postoperative } \\
\hline Stroke & 11 & $\begin{array}{l}335 / 10,328 \\
(3.2 \%)\end{array}$ & $\begin{array}{l}468 / 29,769 \\
(1.6 \%)\end{array}$ & OR 2.23 [1.78-2.80] & $<.00001$ & .04 \\
\hline Respiratory failure & 5 & $\begin{array}{l}608 / 3,589 \\
(16.9 \%)\end{array}$ & $\begin{array}{l}1,221 / 13,335 \\
(9.2 \%)\end{array}$ & OR 2.30 [1.71-3.11] & $<.00001$ & .0006 \\
\hline $\mathrm{HF}$ & 4 & $\begin{array}{l}168 / 3,824 \\
(4.4 \%)\end{array}$ & $\begin{array}{l}333 / 11,725 \\
(2.8 \%)\end{array}$ & OR 1.82 [0.78-4.23] & .2 & $<.00001$ \\
\hline MI & 7 & $\begin{array}{l}241 / 6,527 \\
(3.7 \%)\end{array}$ & $\begin{array}{l}858 / 18,621 \\
(4.6 \%)\end{array}$ & OR 0.98 [0.56-1.71] & .9 & $<.00001$ \\
\hline Length of stay (d) & 6 & $\begin{array}{l}9.8(5.0) \\
(\mathrm{n}=5,157)\end{array}$ & $\begin{array}{l}8.2(3.9) \\
(\mathrm{n}=14,017)\end{array}$ & MD 1.48 [1.09-1.87] & $<.00001$ & $<.0001$ \\
\hline
\end{tabular}

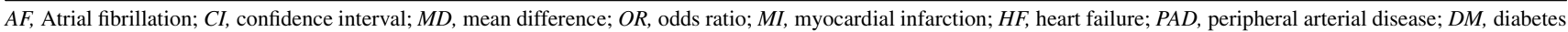
mellitus; $C O P D$, chronic obstructive pulmonary disease; $L V E F$, left ventricular ejection fraction; $A C E I$, angiotensin-converting enzyme inhibitors; $C P B$, cardiopulmonary bypass; $A C$, aortic clamp; IABP, intra-aortic balloon pump; $M I$, myocardial infarction. *Shown as weighted mean (standard deviation) (total) for continuous variables and $\mathrm{n} /$ total ( $\%$ ) for categorical variables. 
weeks. ${ }^{16}$ Higher release of creatine kinase MB has been reported in patients with new-onset $\mathrm{AF}$ as compared with patients without new-onset AF, implying a myocardial injury mechanism. ${ }^{17}$ Increased mortality from new-onset AF may also be related to its treatment, especially with antiarrhythmic medications and anticoagulants. In regard to late mortality with autopsy data, both authors (Mariscalco and Ahlsson) explain late mortality on the basis of higher propensity for subsequent atrial arrhythmias, although the 1-year prevalence of AF after cardiac surgery is reported at $1 \%$ to $2 \%{ }^{18}$ Only 1 study $^{5}$ looked at the absence of predischarge $\mathrm{AF}$ and showed that $\mathrm{AF}$ occurring during follow-up in the group without predischarge AF (but not in the group with predischarge AF) significantly increased the risk of death (hazard ratio 4.44 [1.23-15.99], $P=.023$ ).

Factors associated with new-onset AF. Among the predictive factors for new-onset $\mathrm{AF}$, age, ${ }^{1} \mathrm{COPD},{ }^{2}$ lower LVEF, prior stroke and PAD, and preoperative IABP use were associated with new-onset AF. Interestingly, our study reports increased risk of new-onset $\mathrm{AF}$ from preoperative use of ACEI before CABG. Higher risk of new-onset AF (OR, 1.33 [95\% CI, 1.17-1.51]; $P<.0001)$ and a doubling in mortality risk (OR, $2.83[95 \% \mathrm{CI}, 1.03-7.8] ; P=.04)$ secondary to preoperative ACEI use was also recently shown by Miceli and colleagues ${ }^{19}$ in 3052 patients receiving preoperative ACEI matched 1:1 to a control group by propensity score analysis. A recent study ${ }^{20}$ showed benefit with regard to reduction in new-onset AF, whereas others have not shown any benefit. ${ }^{21,22}$ ACEIs are widely known to decrease the risk of $\mathrm{AF}$ after $\mathrm{MI}$ and cardioversion, but the antiarrhythmic effect of ACEI/angiotensin receptor blocking agents after cardiac surgery at present is at best theoretical. Several mechanisms involving atrial remodeling, including angiotensin II-dependent atrial fibrosis and regulation of angiotensin II-receptor subtypes, have been postulated. Candesartan has been shown to prevent structural atrial remodeling and atrial endothelial dysfunction in hypertensive rats. ${ }^{23}$ Given the limitations of our analysis, we cannot claim that preoperative use of ACEI is independently associated with newonset AF after CABG.

As is widely known, sympathovagal imbalance ${ }^{24}$ may be an important trigger for postoperative new-onset AF; the effect of B-blockers on new-onset AF is thus important but controversial. Some factors make this issue complex. First, it is common practice to routinely use $\beta$-blockers before surgery and to continue in the postoperative period, yet in many cases they may be inadvertently discontinued and not resumed in a timely manner postoperatively. In our analysis, preoperative B-blocker use was fairly comparable between patients in whom new-onset AF developed postoperatively and those in whom it did not, and ß-blockers were shown to be beneficial.
Among the intraoperative factors, CPB time and aortic clamp time were associated with new-onset AF. Aortic clamp time has been proposed as one of the main intraoperative factors predisposing to new-onset AF; however, other studies have not shown this association. ${ }^{25}$

\section{Limitations}

Our study has several limitations. First, and perhaps most important, is that several factors related to new-onset AF also predict early and late mortality. ${ }^{3-5}$ Distinguishing these complications arising out of new-onset AF from the risks related to pre-existing cardiac disease underscores the daunting task of establishing new-onset AF as an independent contributor to mortality. Meta-analyses of published studies by concept allow univariate analysis only and are in no position to address that question. Second, incomplete matching led to exclusion of large numbers of patients in other studies. ${ }^{4,5}$ particularly in the study by Villareal and colleagues, ${ }^{3}$ in which less than $20 \%$ of $\mathrm{AF}$ cases were represented in the matched-set analysis. Although other studies ${ }^{7,9}$ used propensity score matching, this still does not overcome the potential limitation posed by unrecognized and unmeasured confounders. Third, mortality data in most studies were based on all-cause mortality because of limited autopsy data; as such, the mechanisms of postoperative AF-associated mortality remain at best speculative. Fourth, information on long-term mortality risks in individual studies was scarce. With the exception of Mariscalco and colleagues, ${ }^{7}$ published risks did not discount patients who had already died or were lost to follow-up at given time points. This may have introduced bias in calculations of long-term ORs for mortality. Using the information supplied by Mariscalco and associates, we performed a sensitivity analysis to calculate ORs with 2 different denominators (number of patients at baseline versus number of patients at the beginning of the period of interest), and similar ORs were obtained at 6 months, 1 year, and 4 years, probably owing to a low mortality risk on this study. However, this was not the case in other studies, and the risk of bias is still present. Fifth, because our analysis includes several retrospective studies, we cannot exclude the possibility that new-onset AF occurred as a consequence of another postoperative complication, that is, it was a surrogate marker of poor outcome. To overcome this effect, Villareal and colleagues ${ }^{3}$ censored in-hospital mortality while making such comparisons, but the association between new-onset AF and reduced survival persisted. Sixth, new-onset AF occurs at different times in different patients, but none of the studies attempted to find associations between temporal onset of new-onset $\mathrm{AF}$ and time-specific risk factors, nor did they investigate the condition of patients at the onset of new-onset AF to identify possible inciting factors. Thus, in this meta-analysis it was not possible to investigate the impact of an active clinical 
condition or complication at the onset of new-onset AF, nor its immediate consequences, such as occasional acute hemodynamic deterioration secondary to lack of synchronized atrial contraction that may be particularly important for patients with diastolic dysfunction. Last, the studies did not carry enough information regarding medications to explain whether increased postoperative mortality could be related to treatment of new-onset AF or undertreatment of potential thromboembolic risk. In observational studies, sicker patients are often treated, and hence the effects of treatment on outcome are difficult to delineate. However, most centers currently tend to tackle new-onset AF by a formal or informal protocol requiring anticoagulation and chemical or electrical cardioversion, especially if new-onset AF causes hemodynamic compromise.

\section{CONCLUSIONS \\ Implications for Clinical Practice}

Results from the pooled data are too compelling to disregard the association between new-onset AF and early and late mortality after cardiac surgery. Among the modifiable factors, whenever possible less or judicious use of inotropes may help lower the occurrence of new-onset AF, as may shorter $\mathrm{CPB}$ and aortic clamp times during the surgery. Increased use of B-blockers, on the other hand, may also decrease occurrence of new-onset AF. Postoperative/intraoperative IABP use was not associated with new-onset AF.

\section{Implications for Research}

No evidence to support any pathophysiologic mechanisms linking new-onset AF to mortality exists at this time. Risk factors for mortality in cardiac surgical patients are widely established, but risk factors for new-onset $\mathrm{AF}$ have not been well studied, and probably some of them are also risk factors for mortality. Whether this association can be explained by other variables, such as common risk factors for new-onset AF and mortality, remains to be investigated. We could not adjust for these confounders, inasmuch as we used published summary data and did not have access to individual patient data. Future studies need to consider these factors as well as the potential issue of mortality related to treatment of new-onset AF with antiarrhythmics or undertreatment of new-onset AF, particularly in regard to anticoagulation.

\section{References}

1. Cox JL. A perspective of postoperative atrial fibrillation in cardiac operations. Ann Thorac Surg. 1993;56:405-9.

2. Mathew JP, Fontes ML, Tudor IC, Ramsay J, Duke P, Mazer CD, et al. A multicenter risk index for atrial fibrillation cardiac surgery. JAMA. 2004;291:1720-9.

3. Villareal RP, Hariharan R, Liu BC, Kar B, Lee W, Elayda M, et al. Postoperative atrial fibrillation and mortality after coronary artery bypass surgery. $J$ Am Coll Cardiol. 2004;43:742-8.
4. Mariscalco G, Engstrom KG. Postoperative atrial fibrillation is associated with late mortality after coronary surgery but not after valvular surgery. Ann Thorac Surg. 2009;88:1871-6.

5. Almassi GH, Schowalter T, Nicolosi AC, Aggarwal A, Moritz TE, Henderson WG, et al. Atrial fibrillation after cardiac surgery. A major morbid event. Ann Surg. 1997;226:501-11.

6. Aranki SF, Shaw DP, Adams DH, Rizzo RJ, Couper GS, VanderVleit M, et al. Predictors of atrial fibrillation after coronary artery surgery. Circulation. 1996; 94:390-7.

7. Mariscalco G, Klersy C, Zanobini M, Banach M, Ferrarese S, Borsani P, et al. Atrial fibrillation after isolated coronary surgery affects late survival. Circulation. 2008;118:1612-8.

8. Ahlsson AJ, Bodin L, Fengsrud E, Englund A. Patients with postoperative atrial fibrillation have a doubled cardiovascular mortality. Scand Cardiovasc J. 2009; 43:330-6.

9. Kalavrouziotis D, Buth KJ, Ali IS. The impact of new-onset atrial fibrillation on in-hospital mortality following cardiac surgery. Chest. 2007;131:833-9.

10. Mantel N, Haenszel W. Statistical aspects of the analysis of data from retrospective studies of disease. J Nat Cancer Inst. 1959;22:719-48.

11. DerSimonian R, Laird N. Meta-analysis in clinical trials. Control Clin Trials. 1986; 7:177-88.

12. Hravnak M, Hoffman LA, Saul MI, Zullo TG, Whitman GR, Griffith BP. Predictors and impact of atrial fibrillation after isolated coronary artery bypass grafting. Crit Care Med. 2002;30:330-7.

13. Echahidi N, Mohty D, Pibarot P, Despres JP, O'Hara G, Champagne J, et al. Obesity and metabolic syndrome are independent risk factors for atrial fibrillation after coronary artery bypass graft surgery. Circulation. 2007;116(Suppl I):I213-9.

14. Nisanoglu V, Erdil N, Aldemir M, Ozgur B, Berat Cihan H, Yologlu S, et al. Atrial fibrillation after coronary artery bypass grafting in elderly patients: incidence and risk factor analysis. Thorac Cardiovasc Surg. 2007;55:32-8.

15. Bruins P, te Velthius H, Yazdanbakhsh AP, Jansen PG, van Hardevelt FW, de Beaumont EM, et al. Activation of the complement system during and after cardiopulmonary bypass surgery: postsurgery activation involves $\mathrm{C}$-reactive protein and is associated with postoperative arrhythmia. Circulation. 1997;96:3542-8.

16. Shinbane JS, Wood MA, Jensen DN, Ellenbogen KA, Fitzpatrick AP, Scheinman MM. Tachycardia induced cardiomyopathy: a review of animal models and clinical studies. J Am Coll Cardiol. 1997;29:709-15.

17. Ahlsson AJ, Bodin L, Lundblad OH, Englund AG. Postoperative atrial fibrillation is not correlated to C-reactive protein. Ann Thorac Surg. 2007;83:1332-7.

18. Loubani M, Hickey MS, Spyt TJ, Galinanes M. Residual atrial fibrillation and clinical consequences following postoperative supraventricular arrhythmias. Int J Cardiol. 2000;74:125-32.

19. Miceli A, Capoun R, Fino C, Narayan P, Bryan AJ, Angelini GD, et al. Effects of angiotensin-converting enzyme inhibitor therapy on clinical outcome in patients undergoing coronary artery bypass grafting. J Am Coll Cardiol. 2009;54: 1778-84.

20. Ozaydin M, Dede O, Varol E, Kapan S, Turker Y, Peker O, et al. Effect of reninangiotensin aldosterone system blockers on postoperative atrial fibrillation. Int J Cardiol. 2008;127:362-7.

21. Coleman CI, Makanji S, Kluger J, White CM. Effect of angiotensin-converting enzyme inhibitors or angiotensin receptor blockers on the frequency of postcardiothoracic surgery atrial fibrillation. Ann Pharmacother. 2007;41:433-7.

22. White CM, Kluger J, Lertsburapa K, Faheem O, Coleman CI. Effect of preoperative angiotensin converting enzyme inhibitor or angiotensin receptor blocker use on the frequency of atrial fibrillation after cardiac surgery: a cohort study from the atrial fibrillation suppression trials II and III. Eur $J$ Cardiothorac Surg. 2007;31:817-20.

23. Okazaki H, Minamino T, Tsukamoto O, Kim J, Okada K, Myoishi M, et al. Angiotensin II type receptor blocker prevents atrial structural remodeling in rats with hypertension induced by chronic nitric oxide inhibition. Hypertens Res. 2006;29:277-84.

24. Budeus M, Feindt P, Gams E, Weineke H, Sack S, Erbel R, et al. Beta-blocker prophylaxis for atrial fibrillation after coronary artery bypass grafting in patients with sympathovagal imbalance. Ann Thorac Surg. 2007;84:61-6.

25. Mathew JP, Parks R, Savino JS, Friedman AS, Koch C, Mangano DT, et al. Atrial fibrillation following coronary artery bypass graft surgery: predictors, outcomes and resource utilization. Multicenter Study of Perioperative Ischemia Research Group. JAMA. 1996;276:300-6. 